\title{
IMPLEMENTATION OF ARTIFICIAL INTELLIGENCE IN IMPARTING EDUCATION AND EVALUATING STUDENT PERFORMANCE
}

\author{
Dr. N. M. Saravana Kumar, \\ Professor, \\ Department of Computer Science and Engineering, \\ Vivekananda Engineering College, \\ Namakkal, India. \\ saravanakumaar2008@gmail.com
}

\begin{abstract}
Simulation of human intelligence process is made possible with the help of artificial intelligence. The learning, reasoning and self-correction properties are made possible in computer systems. Along with AI, other technologies are combined effectively in order to create remarkable applications. We apply the changing role of AI and its techniques in new educational paradigms to create a personalised teaching-learning environment. Features like recognition, pattern matching, decision making, reasoning, problem solving and so on are applied along with knowledge based system and supervised machine learning for a complete learning and assessment process.
\end{abstract}

Keywords: Artificial Intelligence, Artificial Neural Network, Capsule Network, Educational Technology, Electronic Learning

\section{INTRODUCTION}

Artificial Intelligence is making its place in our day-to-day life at a rapid phase. Researchers and scientists are building innovative approaches in computer modelling, machine learning, probability statistics and decision theory to develop more effective diagnostic methods. AI can perform simple tasks like making a coffee in the morning to complex chores like vacuuming the floor without the need to even touch the vacuum cleaner [2]. There is also a prospective disadvantage of AI becoming too clever.

For over 30 years, research is conducted in implementing artificial intelligence in the field of education. Adaptive learning environment and other tools that are flexible, personalised, effective, inclusive and engaging are being developed and promoted. AI can be defined as a modelling science that is used in investigating, developing and applying formalised models that has salient aspects relevant to learning and instruction. It allows reasoning and derivation of novel facts, which gives a dynamic flavour to the models in use [1]. The adaptive learning environment adapts teaching learning approaches and materials based on the capabilities and requirements of the individual learners. 
In this paper, we propose an artificial intelligence platform that can be used in imparting education as well as evaluating the student performance. It can be modified to adjust to the need of any level of education. The major AI schemes like recognition and pattern matching, decision making and choice, conceptual interface and reasoning, execution and sequential control as well as planning and problem solving are used in the development of the AI platform. For evaluation of student performance, knowledge based systems and supervised machine learning techniques are used.

\section{EXISTING LITERATURE}

The roles and applicability of AI techniques has been continuously changing. The education community is finding innovative ways to productively implement AI for faculty and learners. AI should be leveraged to create an improved student experience. Elon University used AI in order to help students in tracking previously taken courses and help them apply this information in course-planning (Lee Gardner, 2018). AI is used in Free Application for Federal Student Aid (FAFSA) completion, campus tour and class scheduling. Georgia State University uses a chatbot called Pounce, built by AdmitHub that reaches out students through text to intimate incomplete tasks by set dates (Page \& Gehlbacj, 2018).

AI sends reminders to students about important dates. It also provides information to the students such as required classes for program completion and offer of those classes. It allows the faculty to upload notes of the classes online that can be accessed by the students [3]. AI has the ability to recognize an instance of categories, concepts or patterns. AI can draw on inference, planning and execution; monitor development of ideas as they are executed; identify environmental irregularities and modify their plans in return [4]. AI is being used in smart toys and computationally organized scholastic and entertainment materials. Williams et al. [5] uses a programmable, social robot that can guide children's exploration of AI concepts. It helps in a positive understanding of the AI concepts such as planning, reasoning, perception and deep learning.

A lecture robot system [6], is developed that identifies inappropriate behaviour to restructure and replicate the presentation behaviour model. Gaze, pointing gesture and face detection are used by the robot to control the learner's attention and to promote eye the concentration as well as understanding level of the lecture content. AI is the pillar of Natural Language Processing (NLP) assisted intelligent tutor system [7]. It assists in promoting qualities like resolving conflict statements, self-reflection, generating creative questions, answering deep questions and choice-making skills.

Aljohani et al. [8], used Google Home Mini for interacting with students and anticipated to achieve enhanced degree of student accomplishment in physics. Nagao et al. [9], used e-learning aka intelligent tutoring system (ITS) to create user models for learners to improve learning contents.

ISSN: 2582-2012 (online) 


\section{COMPARISON OF AI FEATURES}

Table 1: Comparison of Cognitive Architecture based on [4]

\begin{tabular}{|c|c|c|c|c|}
\hline $\begin{array}{c}\text { Cognitive } \\
\text { Architecture }\end{array}$ & Task Statement & Key Ideas & Assignment & Test Cases \\
\hline $\begin{array}{l}\text { Recognition } \\
\text { and Pattern } \\
\text { Matching }\end{array}$ & $\begin{array}{l}\text { Given - A pattern that } \\
\text { defines some class of } \\
\text { circumstances; An } \\
\text { explanation of certain } \\
\text { explicit conditions. } \\
\text { Find - All ways in } \\
\text { which the pattern equals } \\
\text { the condition. }\end{array}$ & $\begin{array}{l}\text {-The major role of } \\
\text { patterns and pattern } \\
\text { matching in AI } \\
\text {-The relational character } \\
\text { of several patterns and } \\
\text { situations } \\
\text {-A pattern's capacity to } \\
\text { match a condition in } \\
\text { multiple means }\end{array}$ & $\begin{array}{l}\text { Pattern matcher } \\
\text { for established } \\
\text { logic, with } \\
\text { situations stated } \\
\text { as groupings of } \\
\text { relational } \\
\text { ground literals. }\end{array}$ & $\begin{array}{l}\text {-Check } \\
\text { authenticity of } \\
\text { puzzle moves } \\
\text {-satisfaction of } \\
\text { goal explanations } \\
\text {-identify spatial } \\
\text { relations. }\end{array}$ \\
\hline $\begin{array}{l}\text { Decision } \\
\text { making and } \\
\text { Choice }\end{array}$ & $\begin{array}{l}\text { Given - A set of entities } \\
\text { and linked explanations; } \\
\text { A set of goals and } \\
\text { assessment criteria. } \\
\text { Find- A designated } \\
\text { subset of the original } \\
\text { entities. }\end{array}$ & $\begin{array}{l}\text {-Generates candidate } \\
\text { choices from among } \\
\text { accessible entities } \\
\text {-Evaluates and then } \\
\text { chooses from among } \\
\text { these choices } \\
\text {-Uses features of } \\
\text { selections and agent } \\
\text { objectives influence } \\
\text { choices }\end{array}$ & $\begin{array}{l}\text { Tool that } \\
\text { calculates one } \\
\text { or more scores } \\
\text { for each choice, } \\
\text { ranks } \\
\text { substitutes, and } \\
\text { makes final } \\
\text { choice. }\end{array}$ & $\begin{array}{l}\text { Select among } \\
\text { classifications } \\
\text { using a utility } \\
\text { function, choose } \\
\text { among patterns } \\
\text { based on latest } \\
\text { coordinated } \\
\text { elements. }\end{array}$ \\
\hline $\begin{array}{l}\text { Conceptual } \\
\text { Interface } \\
\text { and } \\
\text { Reasoning }\end{array}$ & $\begin{array}{l}\text { Given: A set of } \\
\text { information elements } \\
\text { encoding capability; A } \\
\text { set of beliefs that term } \\
\text { some condition; An } \\
\text { optional query to answer } \\
\text { or goal to realize; } \\
\text { Find: A set of } \\
\text { intellectual chains that }\end{array}$ & $\begin{array}{l}\text {-Constructs proof-like } \\
\text { assemblies that link } \\
\text { beliefs / queries } \\
\text { - Involves a space of } \\
\text { candidate assemblies, } \\
\text { only some of them viable } \\
\text {-Must search this space } \\
\text { to find clarifications to } \\
\text { agents' objectives }\end{array}$ & $\begin{array}{l}\text { Deductive } \\
\text { engine that } \\
\text { conveys out } \\
\text { AND/OR search } \\
\text { through a space } \\
\text { of proof trees. }\end{array}$ & $\begin{array}{l}\text { Queries about } \\
\text { kinship relations, } \\
\text { geometry } \\
\text { statements }\end{array}$ \\
\hline
\end{tabular}


Journal of Artificial Intelligence and Capsule Networks (2019)

Vol.01/ No. 01

Pages: 1-9

http://irojournals.com/aicn/

DOI: https://doi.org/10.36548/jaicn.2019.1.001

\begin{tabular}{|c|c|c|c|c|}
\hline & link facts via knowledge. & & & \\
\hline $\begin{array}{l}\text { Execution } \\
\text { and } \\
\text { Sequential } \\
\text { Control }\end{array}$ & $\begin{array}{l}\text { Given: A description of } \\
\text { the agent's current } \\
\text { condition; Knowledge } \\
\text { elements with } \\
\text { provisional effects of } \\
\text { actions; } \\
\text { descriptions and/or } \\
\text { assessment criteria; } \\
\text { Find: Action instances to } \\
\text { carry out and expected } \\
\text { changes. }\end{array}$ & $\begin{array}{l}\text {-Combines knowledge } \\
\text { and principles to } \\
\text { generate candidate } \\
\text { actions } \\
\text {-Uses knowledge about } \\
\text { agent purposes to } \\
\text { evaluate alternatives } \\
\text {-Selects a subset of } \\
\text { actions and conveys } \\
\text { them out before } \\
\text { continuing }\end{array}$ & $\begin{array}{l}\text { Procedure that } \\
\text { repeatedly } \\
\text { matches, } \\
\text { chooses, } \\
\text { implements } \\
\text { actions; } \\
\text { extensions for } \\
\text { interpretation } \\
\text { and task- } \\
\text { directed } \\
\text { processing. }\end{array}$ & $\begin{array}{l}\text { Control first- } \\
\text { person game } \\
\text { agent, method } \\
\text { objects while } \\
\text { dodging } \\
\text { obstacles, HTN } \\
\text { to collect / } \\
\text { assemble objects. }\end{array}$ \\
\hline $\begin{array}{l}\text { Planning } \\
\text { and } \\
\text { Problem } \\
\text { Solving }\end{array}$ & $\begin{array}{l}\text { Given: Knowledge about } \\
\text { conditional effects of } \\
\text { actions; An explanation } \\
\text { of the agent's current } \\
\text { situation; A set of goals } \\
\text { and/or assessment } \\
\text { criteria; } \\
\text { Find: Plans to convert } \\
\text { current state into one } \\
\text { that satisfies goals. }\end{array}$ & $\begin{array}{l}\text {-Involves mental } \\
\text { simulation of action } \\
\text { sequences } \\
\text { execution) } \\
\text {-Requires agent to search } \\
\text { over a space of } \\
\text { alternative plans } \\
\text {-Uses heuristics to guide } \\
\text { this search and make it } \\
\text { manageable }\end{array}$ & $\begin{array}{l}\text { A planning } \\
\text { system that } \\
\text { examines } \\
\text { through space of } \\
\text { candidate plans, } \\
\text { using same } \\
\text { formalism as } \\
\text { serial control. }\end{array}$ & $\begin{array}{l}\text { Same as for the } \\
\text { serial control } \\
\text { assignment. }\end{array}$ \\
\hline
\end{tabular}

\section{PROPOSED WORK}




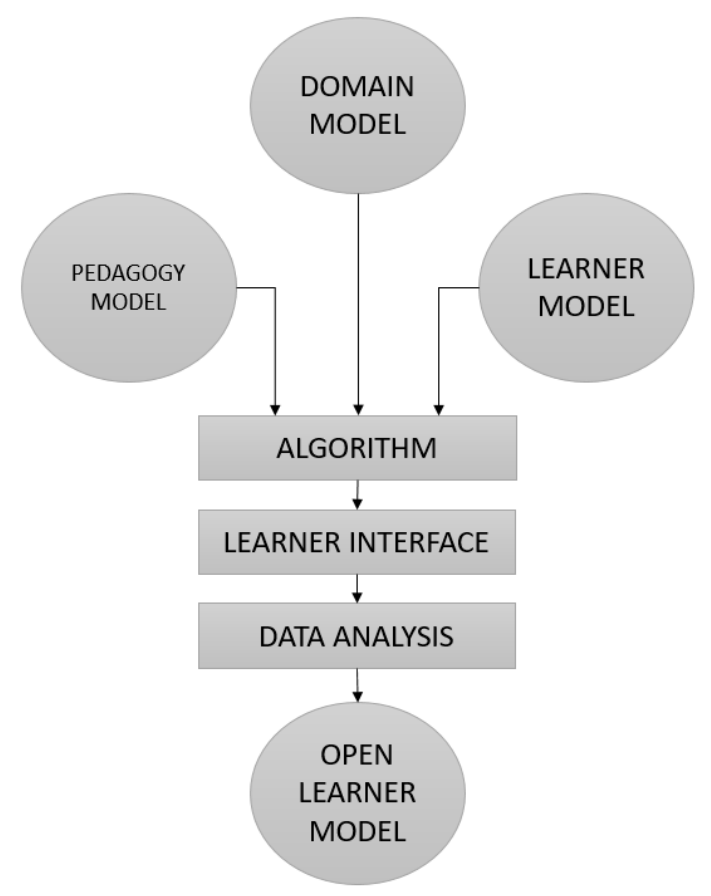

Figure 1 AI based education model

We develop a complete AI based education system that consists of a computer based system that helps in course selection, based on the set of previous subjects and score. Once the course is chosen, alerts are being sent via Google assistant or text. Further, the classes are conducted by lecture robots that can control the attention of the student with the help of sensors and technology to track gaze and detect faces. The materials are made available online with the help of cloud storage for students to be able to access at any point of time from any place. Student doubts are clarified online. Further, assessment and evaluation is done with the help of knowledge based system and supervised machine learning techniques.

The AI based education model consists of an algorithm that encompasses domain model, pedagogy model and learner model. These factors are combined together to form a complete algorithm that processes the knowledge represented in the models. This algorithm is then fed to the learner interface that comprises of adaptive content in the form of text or video that can be adapted to the need and efficiency of individual learner and data capture that monitors the interactions of the learner. Further, data analysis involves machine learning and pattern recognition. Finally all these factors lead to the creation of an open learner model that makes learning explicit for both faculty and the learners.

\subsection{Course Selection Methodology}


With the help of NLP, fuzzy logic, expert system and neural network, a fundamental expert system is built that can assist the students in selecting courses that are best suited for them. This selection is done based on the previous courses taken by the students. Courses can be chosen and tailored based on the student capabilities and needs. The analysis of previous courses, their outcomes and the learner's achievements also act as the base for selection of courses.

\subsection{LectureBot}

Robotics is a major domain of AI that establishes robots as artificial agents of real-time environments. Here, we use them as teaching agents that offer regulation, monitoring and explanation to track the learner's mental steps. The lecturebot comes with an LED screen on the robot which projects several 3D illustrations with the help of dynamic graphical user interfaces. It can substitute for lecturers and reconstruct the non-verbal behaviour of the lecturers as well.

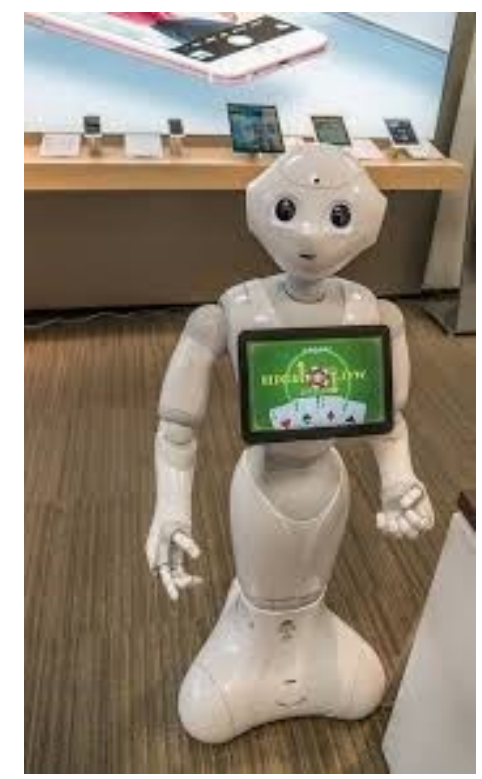

Figure 2 LectureBot

\subsection{Cloud Storage}

Cloud storage enables the storage of teaching and learning materials online. It helps in creating a global classroom that leads to interconnection and accessibility of classrooms globally. Virtual mentors are developed with the technologies found in Siri and Google. Interactive content and educational database such as video 
lectures, e-books, individual assessment of teaching agents and natural games are synthesized and organized. This also enables student interaction and helps in making the model learner centric.

\subsection{Assessment and Evaluation}

Knowledge based systems use a set of "if-then" statements to perform induction. It is expensive and difficult to build as it requires more human input in the form of rules in order to execute well. Machine Learning is based on statistical modelling. It is a supervised learning system in which the classifier must be trained with formerly interpreted data. In supervised learning, the machine is trained using data which is labelled and tagged with correct answer. This helps in prediction of outcomes for unpredicted data.

\section{RESULT}

The proposed system offers a complete smart learning environment with artificial intelligence that assists the learner from course selection to evaluation and even certification. It also helps the instructor in lecture preparation and maintenance of course content in the cloud database and also to follow student progress as all the data is created and updated online.

\section{CONCLUSION AND FUTURE SCOPE}

The AI based smart learning system that involves intelligent tutoring and virtual reality is composed of the key features of AI like Recognition and pattern matching, Decision making and choice, Conceptual Interface and Reasoning, Execution and Sequential Control, Planning and Problem Solving. The qualitative assessment of student performance is based on Knowledge-Based System (KB) and Supervised Machine Learning (SL). Future work involves implementation of the lecturebot prototype and loading it with multiple features and capabilities for enabling the provision of a complete learning experience.

\section{References}

[1] Luckin, Rose, Wayne Holmes, Mark Griffiths, and Laurie B. Forcier. "Intelligence unleashed: An argument for AI in education." (2016). 
Journal of Artificial Intelligence and Capsule Networks (2019)

Vol.01/ No. 01

Pages: 1-9

http://irojournals.com/aicn/

DOI: https://doi.org/10.36548/jaicn.2019.1.001

[2] Andriessen, Jerry, and Jacobijn Sandberg. "Where is education heading and how about AI?" International Journal of Artificial Intelligence in Education 10, no. 2 (1999): 130-150.

[3] Barrett, Mandy, Lisa Branson, Sheryl Carter, Frank DeLeon, Justin Ellis, Cirrus Gundlach, and Dale Lee. "Using Artificial Intelligence to Enhance Educational Opportunities and Student Services in Higher Education." Inquiry: The Journal of the Virginia Community Colleges 22, no. 1 (2019): 11.

[4] Langley, Pat. "An Integrative Framework for Artificial Intelligence Education." (2019).

[5] Williams, Randi, Hae Won Park, Lauren Oh, and Cynthia Breazeal. "PopBots: Designing an Artificial Intelligence Curriculum for Early Childhood Education." (2019).

[6] Ishino, Tatsuya, Mitsuhiro Goto, and Akihiro Kashihara. "A robot for reconstructing presentation behavior in lecture." In Proceedings of the 6th International Conference on Human-Agent Interaction, pp. 67-75. ACM, 2018 .

[7] Malik, Garima, Devendra Kumar Tayal, and Sonakshi Vij. "An analysis of the role of artificial intelligence in education and teaching." In Recent Findings in Intelligent Computing Techniques, pp. 407-417. Springer, Singapore, 2019.

[8] Aljohani, Nouf. "Artificial Intelligence (AI) and the Educational Process: Using AI to Enhance Student Performance in Content Skills." In Kansas State University Khbrat SUMMIT. Manhattan, KS: Kansas State University, Center for Intercultural and Multilingual Advocacy in the College of Education and the English Program, 2019.

[9] Nagao, Katashi. "Artificial Intelligence in Education." In Artificial Intelligence Accelerates Human Learning, pp. 1-17. Springer, Singapore, 2019.

[10] McArthur, David, Matthew Lewis, and Miriam Bishary. "The roles of artificial intelligence in education: current progress and future prospects." Journal of Educational Technology 1, no. 4 (2005): 42-80.

[11] Devedžić, Vladan. "Web intelligence and artificial intelligence in education." Educational technology \& society 7 , no. 4 (2004): 29-39. 
Journal of Artificial Intelligence and Capsule Networks (2019)

Vol.01/ No. 01

Pages: 1-9

http://irojournals.com/aicn/

DOI: https://doi.org/10.36548/jaicn.2019.1.001

[12] McCalla, Gordon. "The fragmentation of culture, learning, teaching and technology: implications for the artificial intelligence in education research agenda in 2010." International Journal of Artificial Intelligence in Education 11, no. 2 (2000): 177-196.

[13] Yin, Robert K., and Gwendolyn B. Moore. "The use of advanced technologies in special education: Prospects from robotics, artificial intelligence, and computer simulation." Journal of Learning Disabilities 20, no. 1 (1987): 60-63.

[14] Roll, Ido, and Ruth Wylie. "Evolution and revolution in artificial intelligence in education." International Journal of Artificial Intelligence in Education 26, no. 2 (2016): 582-599.

[15] Blanchard, Emmanuel G., Boris Volfson, Yuan-Jin Hong, and Susanne P. Lajoie. "Affective artificial intelligence in education: From detection to adaptation." In AIED, vol. 2009, pp. 81-88. 2009.

[16] Timms, Michael J. "Letting artificial intelligence in education out of the box: educational cobots and smart classrooms." International Journal of Artificial Intelligence in Education 26, no. 2 (2016): 701-712.

[17] Siau, Keng. "Impact of artificial intelligence, robotics, and automation on higher education." (2017).

[18] Wang, Ruolan, José Reis-Jorge, Lucilla Crosta, Anthony Edwards, and Mageswary Mudaliar. "The use of social media and artificial intelligence tools by online doctoral students at the thesis stage." In Proceedings of Teaching and Education Conferences, no. 8010380. International Institute of Social and Economic Sciences, 2018.

[19] Kandlhofer, Martin, Gerald Steinbauer, Sabine Hirschmugl-Gaisch, and Petra Huber. "Artificial intelligence and computer science in education: From kindergarten to university." In 2016 IEEE Frontiers in Education Conference (FIE), pp. 1-9. IEEE, 2016.

[20] Yu, DanDan, MuRong Ding, WenJing Li, Limin Wang, and Bin Liang. "Designing an Artificial Intelligence Platform to Assist Undergraduate in Art and Design to Develop a Personal Learning Plans." In International Conference on Human-Computer Interaction, pp. 528-538. Springer, Cham, 2019.

[21] Chassignol, Maud, Aleksandr Khoroshavin, Alexandra Klimova, and Anna Bilyatdinova. "Artificial Intelligence trends in education: a narrative overview." Procedia Computer Science 136 (2018): 16-24.

ISSN: 2582-2012 (online) 
Journal of Artificial Intelligence and Capsule Networks (2019)

Vol.01/ No. 01

Pages: $1-9$

http://irojournals.com/aicn/

DOI: https://doi.org/10.36548/jaicn.2019.1.001

[22] Canbek, Nil Goksel, and Mehmet Emin Mutlu. "On the track of artificial intelligence: Learning with intelligent personal assistants." Journal of Human Sciences 13, no. 1 (2016): 592-601.

[23] Ma, Yizhi, and Keng L. Siau. "Artificial Intelligence Impacts on Higher Education." In Proceedings of the Thirteenth Midwest Association for Information Systems Conference, vol. 42, pp. 1-5. 2018.

[24] Wang, Fei, and Xinrong Tao. "Visual Analysis of the Application of Artificial Intelligence in Education." In 2018 International Joint Conference on Information, Media and Engineering (ICIME), pp. 187-191. IEEE, 2018. 